\title{
The Design and Implementation of Yu-County Water Supply Payment Management Information System
}

\author{
Tiantian Guo ${ }^{1, \text { a }}$, Rongqiang Liu ${ }^{2, b}$ \\ ${ }^{1}$ School of Management, Tianjin University of Technology, Tianjin 300384, China \\ ${ }^{2}$ Account manager, Tianhe branch of Tianjin bank, 300111, China \\ agtt916h@163.com, ${ }^{b}$ liurq1989@163.com
} Keywords: Management information system, tap water, pays cost of water supply, database, the
program design.

\begin{abstract}
In order to comply with the development direction of the water supply system of domestic and foreign, the use of SQL Server 2005 as a database development tool, Visual Studio.NET 2005 as a development tool for $\mathrm{C} \#$ as the programming language, design and development of computer-based information processing of human-computer system. In this paper Yu-County, Zhangjiakou City, Hebei Province supply payment system as an example, business process integrate and excellent specification In the management of the introduction of advanced science and technology and management methods, increase scientific and technological content, in order to reduce traffic pressure of the water department to ensure standardization and process management. Through the water supply payment system, it can effectively monitor the ratio of the Water Supply and water storage capacity, the reasonable control of water consumption, propelled to adjust the excess water tariff levels, and provides intelligent decision support, so that the water company in Yu-County efficient operations. As well, it could provide suggestions for other water company to design system.
\end{abstract}

\section{Introduction}

The regeneration and utilization of energy has been a concern of human beings. With the increasing shortage of water resources, the government and relevant departments take the corresponding measures to implement paid use of tap water. With the popularization of information technology, people are accustomed to using computer technology to accomplish a large number of storage and processing of complex information, which not only simplifies the data processing, but also improves the management efficiency. With the progress of science and technology, the information construction of enterprise's operation system becomes very important. City water supply system is an important part of city construction, which provides the water for the city people's life and production. It is an important basis for the survival and development of all walks of life.

Yu-County water payment system using traditional management methods over the years, the situation of water supply and storage recorded and filed in paper form, payment systems and a half information, to produce too much data forms and paper-based information reporting increased the burden on the archive file sections, reducing efficiency. Through needs analysis, design and development of an adaptation to local conditions of the water supply company payment management information systems [1]. Water payment management system helps to achieve standardization and automation sector management, dispersible users can be implemented standardized management to the use of water, the establishment of classification number, form an integrated source of information, to get rid of paper records archives, and scientific management of the water supply system of payment, improve work efficiency and ensure the accuracy and reliability of water users information, improve customer satisfaction. 


\section{Research for System Background}

Domestic water industry is very early to start using the computer for business processing, but mostly limited to the completion of the specific business and data processing. Due to the limit of the national conditions of our country, it is generally used to pay the way of the traditional meter reading. With the constantly improvement of the residential level, some high-grade residential tenants established remote automatic meter reading system, completed by the central management of computer data acquisition and monitoring, but only for to focus on residential areas, and the cost is high [2]. IC card water meter sale management system is the current charging method of, but due to the high cost of the IC card table, coupled with the meter running environment difference, the quality of IC card table requirements is extremely strict, and brings some difficulties for the promotion. With the development of GPRS and 4G technologies, the system can really do real-time processing and real-time control.

This system collects the raw data from the Yu-County water supply department [3], which includes the standard management information system including water supply, charge, copy meter, basic information management and so on. It provides a modern management method for the water supply management, which ensures the timeliness, correctness and completeness of all kinds of data, and effectively improves the management system and improves the management level.

\section{Systems Analysis}

\subsection{Business Process Analysis.}

Through the status of Yu-County water supply department to pay fees management system feasibility analysis and demand analysis [4], this study in-depth understanding of business processes and data flow, as well as public water supply industry and specificity [5], on this basis, come to the preliminary development plan, and then design the system.

According to the business process diagram of the basic specification [6], According to the basic rules of business process chart, combined with the actual situation of water supply management in Yu-County water supply department, the corresponding business process chart is designed.

\subsection{Data Flow Analysis.}

Data flow analysis [7] is the data information, which is independent of the system's internal flow. Data flow chart is the main tool of data flow analysis, and also the main tool to describe the system logic model. It in accordance with the business process diagram of the sorting out the order of business flow, extract the information processing, showing system includes all kinds of data and information, and they are how the data flow together [8].

Yu-County water supply management system top-level data flow chart shown in Figure 1. 


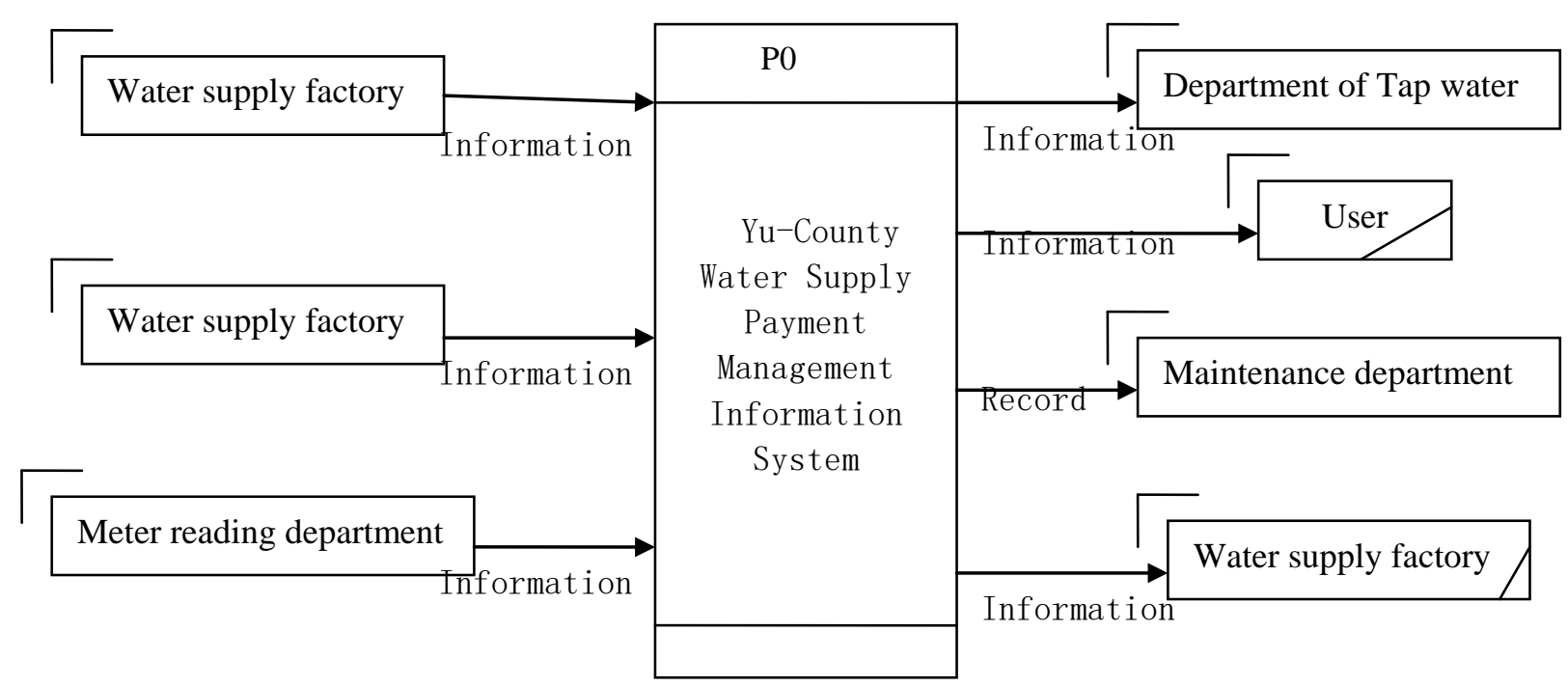

Fig. 1 The top layer data flow diagram of Yu-County water supply payment management system

\section{System Design}

The system data flow system logic model as the main basis for design, using a structured design methodology (SD method), in accordance with the overall design of the system function module structure, the organization will be divided between the various modules, each module according to their affiliation relationship to form a general framework [9]. Yu-County water supply payment management information system, and its main function is divided into: system management, basic information management, user management meter, meter reading input management, payment management, water management, statistical inquiry management, exit the system these parts.

\section{System Implementation}

\subsection{System Key Technologies.}

Connection function of this system is to connect to the database and the system itself up in the form of database access system [10]. As shown in Figure 2.

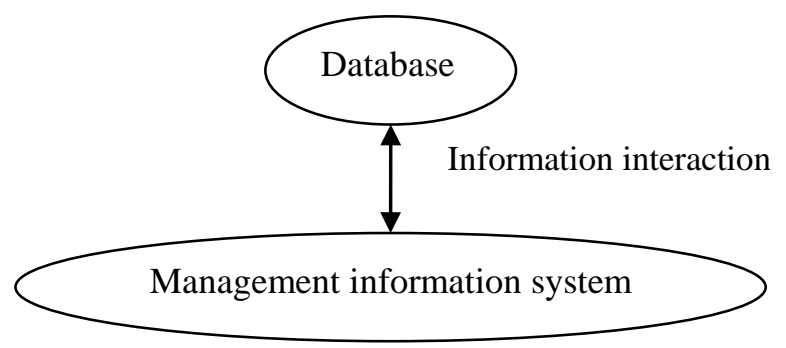

Fig. 2 Database connection function model

The data validation includes data integrity verification, median test, to ensure the correctness of data input and effectiveness.

Fuzzy queries complex conditions. In the query function of a number of conditions dataGridView where composite query database information, but can also unconditionally query. So if you need to rely on statements and SQL language to add conditions to achieve.

ListBox read the database information function. The system uses a container with list Box to read the table information is displayed one by one. 
The arrears fee function of reminding. When a table in the system if there is not paying users, when permissions for meter readers operator logs in, it will prompt the operator to enter the print arrears management information, as the case door reminder fee. And open the appropriate form.

\subsection{Characteristic Technology and Function.}

This system adopts the following characteristics technology to better operating system: menu according to the authorization to display different interface function, with associative query function of the ComboBox data binding function, form between the information transfer function (including rely on information about the multi table update and close a form of instantiated into another form), automatic generation of code function, in the system calls the external procedure function, export excel function, print function, crystal report function, data backup, account telephone contact location and number of regular expressions, judgment function.

\section{Summary}

Through research Yu-County water companies in the water sector contributions, systems analysis and design outlined in this paper Yu-County water payment management information system has been basically completed. This system is the water company for the water charges Yu-County sector designed to complete the objective needs analysis to meet the needs of its basic functions, but there are still many deficiencies. Where the shortage of places in the future will gradually improve in Yu-County expansion and urban water users have been expanding in the process of maturing of the system, operating to be more simple, convenient and practical.

\section{References}

[1]. Huacheng Xue. Management information system (Fourth Edition). Beijing: Tsinghua University Press. 2003.

[2]. Jianxin Qin, Xiaofang Wei, Lang Liao, et al. Design and application of urban water management information system. Geo-Information Science. Vol. 7 (2005) No. 1, CLC: P208; TU991.

[3]. Zhong An. Management information system. China Railway Press, 2009.7.

[4]. Zunqi Yang. Analysis and design of information systems. Beijing: Mechanical Industry Press, 2007.7.

[5]. Jeffrey (US) D.ULLman, Jennifer Windom. A First Course in Database Systems [5] (Edition Second). Beijing: Mechanical Industry Press.2006.

[6]. Shixuan SA, Shan Wang. Introduction to database systems (Third Edition). Beijing: Higher Education Press. p. 101-106, 122-123, 203-240.

[7]. Gary B. Shelly Thomas J. Cashman. Systems Analysis and Design (English. 5th edition). Machinery Industry Press.

[8]. Gang Li. Visual C \# programming tutorial. Tsinghua University Press, 2005.1.

[9]. Deliang Duan, Jian Yu, Rencai Zhang. C \# curriculum design case intensive series. Beijing: Tsinghua University Press, 2008.6.

[10] Ling Jiang, Pingli Yang, Mei Yang, et al. Based on ADO.NET technology to access the Server SQL database programming to achieve [J]. Modern Electronics Technique, Vol. 37 (2014) No. 8, p. 95-98. 